\title{
The Impact of 'Shockvertising' on Consumer Behavior: Investigating Its Influence on the "Why Buy" Aspect
}

\author{
TAReq Nael Hashem ${ }^{1}$, Mohammed S. Alnsour ${ }^{2}$, NAfez Nimer Ali ${ }^{3}$, Firas Nael Hashem ${ }^{4}$, \\ ABDUlRahman NAEl HaShem ${ }^{5}$, OMAR SAlEH MOH"D ABU HAMIDEH ${ }^{6}$ \\ ${ }^{1}$ Marketing Department, Isra University, Amman, JORDAN. \\ ${ }^{2}$ Al-Balqa Applied University, JORDAN. \\ ${ }^{3}$ Marketing Department, Business College, AL Zaytoonh University of Jordan, JORDAN. \\ ${ }^{4}$ College of Business, Tafila Technical University, JORDAN. \\ ${ }^{5}$ Faculty of Administrative and Financial Sciences, Isra University, Amman, JORDAN. \\ ${ }^{6}$ Marketing Department, Business College, AL Zaytoonh University of Jordan, JORDAN.
}

\begin{abstract}
Current study focused on highlighting the influence of shockvertising (Disgusting Images, Sexual References, Profanity/Obscenity, Vulgarity, Impropriety, Moral Offensiveness and Religious Taboos) on consumer behavior in its two dimensions of repurchase intention and word of mouth. Through depending on quantitative approach and utilizing a questionnaire as a tool; researcher distributed on (431) Jordanian consumers within the online social platforms due to COVID 19 lockdown and quarantine. Through SPSS, results of study indicated that shockvertising - along with its variables - plays a role in negatively influencing consumer behavior, analysis also revealed that using religious taboos as advertisement material was the most influential aspect of shockvertising as people tend to act emotionally in reference to their religion, also, results indicated that shockvertising an influence consumer behavior variables and mostly repurchase intention as a consumer is welling to boycott a brand if it presented any offending ad.
\end{abstract}

Key-Words:- Shockvertising; Shock Advertising; Consumer Behavior; Offensive; Surprising; Racist; Religious

Received: May 10, 2021. Revised: October 12, 2021. Accepted: October 23, 2021. Published: November 2, 2021.

\section{Introduction}

Shockvertising (shock advertising/ shock marketing) is a type of advertisement that is used to surprise the audience through deliberate violation of social values standards, personal ideals, rules, values and norms, in order to attract the attention of the recipient and spread the idea and talk about it among people, using horrific images of intimidation or bold or provocative messages, in order to sell a product or present a message as public service to change the behavior of the recipient [18].

The beginning of the appearance of the shocking advertisement has not been decided conclusively, but this may be because this term did not appear until the 1980s, specifically in 1982, with the appearance of the first shocking advertising campaign for the Italian company, Benetton, [7] which is one of the leading companies in the field of shocking and controversial advertisements, and this happened when the company enlisted the help of fashion photographer "Oliviero Toscani", who carried out a multi-ethnic advertising campaign under the slogan (United Colors of Benetton), and here the focus was on the educational message more than the product itself, as Oliver believed that the advertisement would be more effective when addressing an ethical message, regardless of Marketing the product itself, which was not uncommon at the time [13].

Generally speaking, shockvertising violates social values which are the acceptable and unacceptable behavior recognized among people through the process of social learning, in order to evaluate ideas, actions and people [2]. If the advertisement respects that and does not contradict society's perceptions of good, and does not violate these standards, then it is an acceptable declaration by the recipients, but if it violates advertising which are the standards of good taste and personal morals and make the recipient embarrassed and uncomfortable and in some cases, like mental disorder and an increase in heartbeat upon exposure to the shock announcement, this may lead to a backlash that may lead to a boycott of the trademark [17].

\section{Problem Formulation}

Current study aimed at examining the impact of shockvertising on consumer behavior; the aim included objectives of highlighting the correlation between shockvertising and consumer behavior from a marketing perspective. In addition to that, the 
correlation between the two variables will be seen in relation to the aspect of "why buy" that focuses on repurchase intention and word-of-mouth.

Novelty of current research stemmed from the fact that organizations became more daring to try new strategies especially with the development of technology and the deep interaction between technology and organizational performance. From that point, organizations now are exploiting their closeness to customers through social media, and they are using applying new aspects that would help increasing their profit and polish their reputation. In order to realize aim of study; researcher built a model that highlights the relationship between study variables:

\section{Independent Variable}

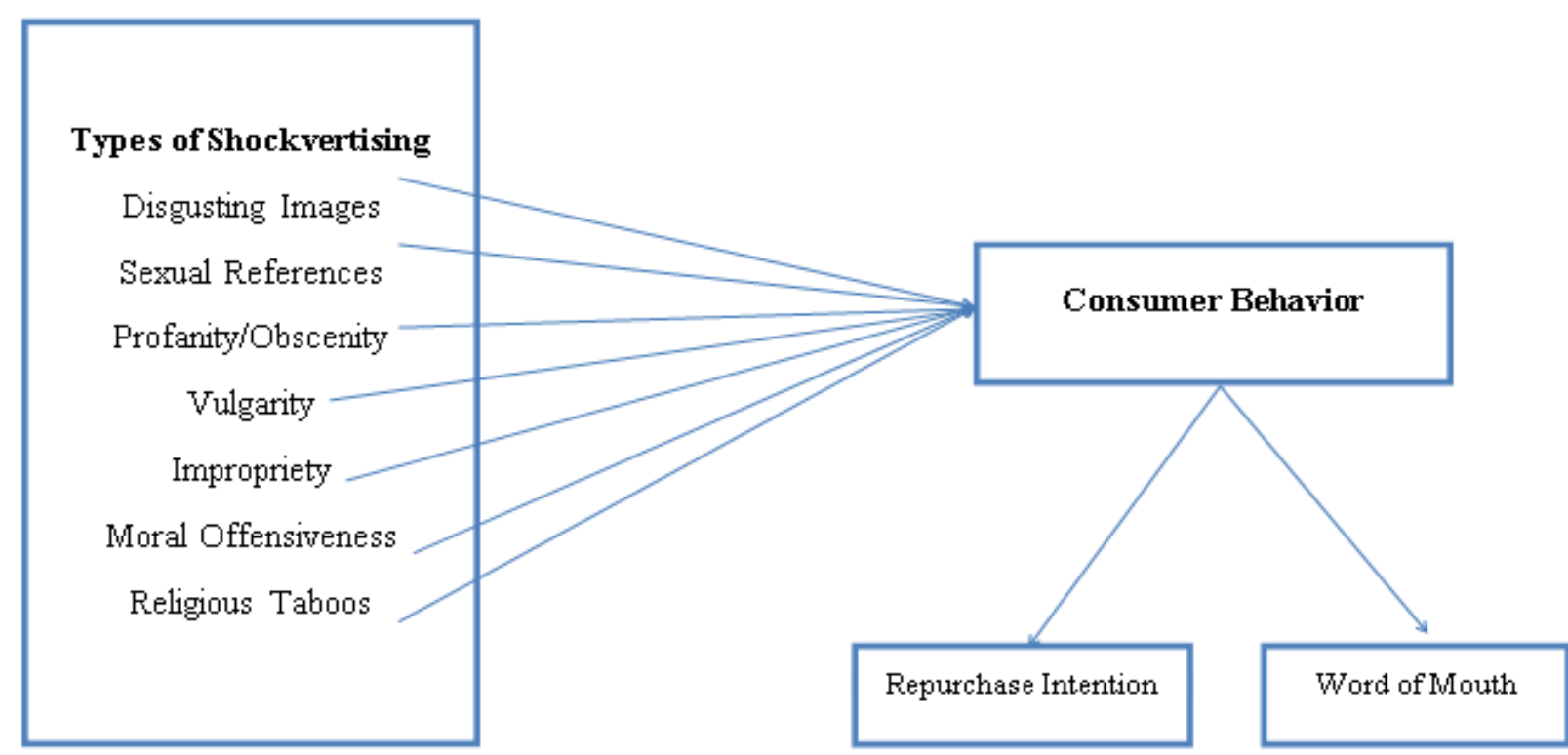

\section{Dependent Variable}

\section{Fig. 1: Study Model [22]}

From above model, researcher was able to extract following set of hypotheses:

\section{Main hypothesis}

H: Shockvertising has the ability to influence consumer behavior

\section{Sub-hypotheses:}

H1: Disgusting Images has the ability to influence consumer behavior

H2: Sexual references has the ability to influence consumer behavior

H3: Profanity has the ability to influence consumer behavior

H4: Vulgarity has the ability to influence consumer behavior

H5: Impropriety has the ability to influence consumer behavior

H6: Moral offensiveness has the ability to influence consumer behavior

H7: Religious taboos have the ability to influence consumer behavior. 
interest of the individual and the group together [8]; [10]; [11]; [12].

Many organizations have tended to use the shocking advertisement to promote their products and services in order to raise the level and strength of the advertisement's impact on the viewer and to stimulate the desire to acquire the product or to stop work such as sending text messages while driving, not fastening the seat belt, children sitting in the other seat dedicated to them and many general issues that attract the public's attention [6].

Shocking advertising method has been used by many organizations to market and promote their products in an implicit and indirect way, such as Benetton, which used ads to stop racism in promoting its products, as in the picture below:

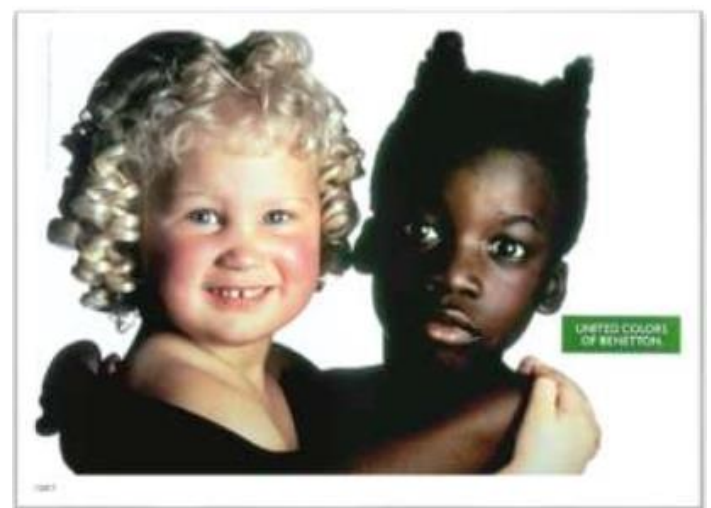

Fig. 2: Shockvertising by united colors of Benetton [5]

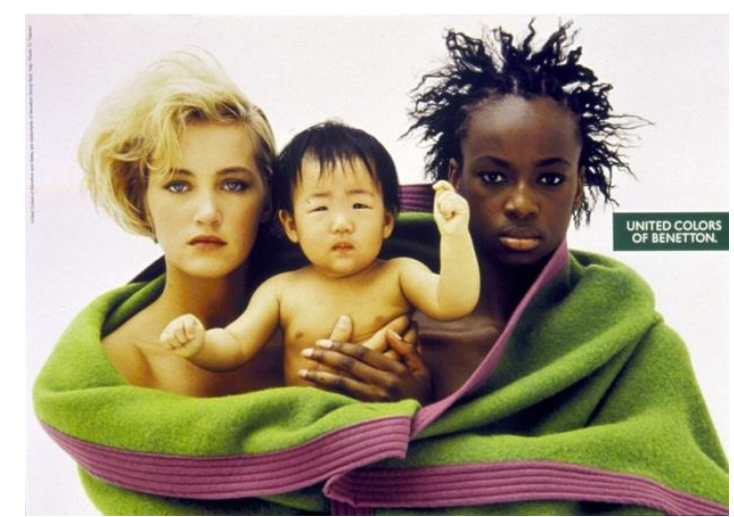

Fig. 3: Shockvertising by united colors of Benetton [5]

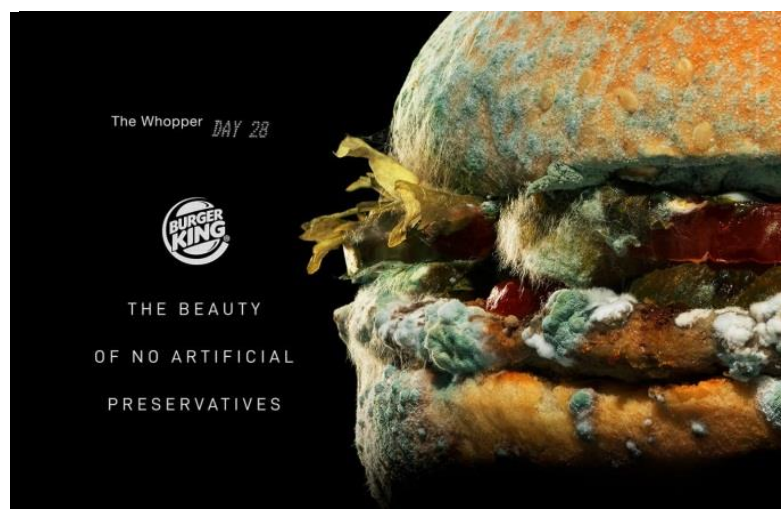

Fig. 4: Shockvertising by Burger King [9]

Therefore, many organizations have tended to employ shockvertising in their advertisements to increase the impact and power of advertising and to increase the individual's awareness of their products and their brand [16]. These organizations linked - as Benetton did - their advertisements to various social issues such as the necessity to fasten seat belts while driving, sexually transmitted diseases, HIV / AIDS, smoking, or the great humanitarian issues such as child abuse, family violence, harassment, or defending someone Forms of injustice in general, such as racism [4].

The idea of the relationship between the shocking advertisement and consumer behavior is one of the relationships that we talked about less due to its recentness. The impact of some types of shocking advertising such as "ethical principles", and there is a close relationship between the consumer's buying behavior and the nature of the shocking advertisement, which may lead to a change in the brand image of the consumer, which would not repeat the purchase experience again [22]. On the same track, it has been pointed out that despite the presence of a lot of resentment and surprise for some types of shocking ads, but it has become a popular means of marketing in order to convey marketing content in a way that attracts attention, and it was confirmed that the shocking advertisement is no longer a means only for marketing rather [1], it is being used today in order to work on changing the different ideas and attitudes of individuals by stirring up their emotions and strengthening their reactions. And the researcher pointed out that the shocking advertisement has a strong impact on consumer behavior, especially social advertising, more than commercial marketing because of its ability to touch many societal aspects that may provoke an individual's anger or draw his attention to a specific idea or topic.

There are many factors that affect consumer behavior such as price, presentation and promotion, location, style and various human factors, but the 
shocking advertising style - which recently appeared in the fields of marketing and its science - has proven its great ability to influence consumer behavior [20]. And his intention to repurchase and even transfer it to a specific service or product level to other individuals [16]. Shocking advertising is based on reaching advertisements that touch sensitive aspects of individuals' environment such as race, ethnicity, religion, cultural background and many more, and these factors - if they are of great boldness - will not only change the behavior of the consumer, but they are able to negatively affect the organizational reputation of the brand as a result of the difference in individual response to these ads, which makes it dangerous due to the ambiguity of the way they affect [19].

It is possible to view the shocking advertisement as a response to the idle and stereotypical state present in most of the current advertisements and an attempt to reduce the repetition in it in order to ensure that the competitive forces are not weakened, which would harm the advertising field. Familiar and at the same time enjoying innovation and creativity that enables the marketer to stand up to competing ads and enjoy a competitive value distinguished from others [14]. On the same idea, shockvertising is characterized by its distinguished appearance and its unprecedented prominence among many advertisements, which makes it intrusive to the attention of the recipient and obsessed with it, and all of this creates a competitive position that is not underestimated emotionally about the advertisement, in the event that an appropriate shock is used to the recipient, not severe, so as not to lead to alienation and disapproval of the advertisement [15].

Shockvertising affects the recipient sensibly when they perceives it with their senses and emotionally when they interacts with it with their emotions and mentally when they evaluate it with their mind, and therefore the shockvertising must be proportional to all perceptual aspects until its ability to infiltrate the attention of the recipient is complete even if the advertisement is between different competitive forces. The image used in the advertisement is the main focus of attracting attention, especially if the image is shocking such as a shockvertising, because with these unique features of dazzling, imagination and out of the ordinary, the competitive advertising value has increased and made it able to create an unprecedented psychological interactive framework between the advertisement and the recipient, it raised the effectiveness of the advertising message [21].

\section{Methods}

Current study adopted the quantitative approach in order to reach the previously set aim. For that sake, a questionnaire was developed by researcher through the aid of previous studies. The questionnaire was built on liker 5 scale and consisted of two main sections, the first took into perspective demographics of study sample; while the other presented statements related to study variables including elements of shockvertising (Disgusting Images, Sexual References, Profanity/Obscenity, Vulgarity, Impropriety, Moral Offensiveness and Religious Taboos) and consumer behavior (repurchase intention and word of mouth). Population of study consisted of Jordanian consumers, a convenient sample of (500) individuals was chosen to represent study population. The questionnaire of study was uploaded online in order to reach as much individuals as possible. Researcher left the questionnaire online for a time of (8) weeks. After that time, responses were extracted on an excel sheet from Google Forms, it was found out that (431) questionnaires were valid for statistical analysis which indicated a response rate of $86.2 \%$.

SPSS was used in order to process collected data, Cronbach alpha test was employed in order to measure reliability of instrument, it appeared that alpha value for each variable was good because it was higher than the acceptable ratio of 0.60 as shown in the following table:

Table 1. Reliability Test

\begin{tabular}{lc|} 
& Alpha Value \\
\hline Disgusting Images & 0.79 \\
\hline Sexual References & 0.702 \\
\hline Profanity/Obscenity & 0.794 \\
\hline Vulgarity & 0.864 \\
\hline Impropriety & 0.762 \\
\hline Moral Offensiveness & 0.838 \\
\hline Religious Taboos & 0.813 \\
\hline
\end{tabular}




\section{Analysis and Discussion}

Current study aimed at examining the influence of shockvertising on consumer behavior in terms of repurchase intention and word of mouth. Through adopting quantitative approach; (431) individuals were exposed to a questionnaire. Results of study were as follow:

sample characteristics according to presented demographics were analyzed; it appeared that majority of individuals responded to questionnaire were females scoring a mean of $55.9 \%$ who ranged between the age of $40-50$ years old scoring $43.2 \%$ with a graduate level of education $55.2 \%$, married $59.2 \%$ and with an income of less than $\$ 500$ scoring a mean of $48.3 \%$ of total sample.
Also, it appeared through analysis that respondents had a positive attitude towards statements of questionnaire given that all statements scored higher than mean of scale 3.00 which is seen to be statistically positive.

Such results gave a clear indication that respondents dealt with the questionnaire in a positive way due to its clarity, and consistency which enabled respondents to understand each statements and answer to it according to their orientation.

In table (2) below, mean and standard deviation was calculated for each variable of study, it can be seen that respondents had a positive attitude towards variables given that all of them scored higher than mean of scale 3.00 .

Table 2. Descriptive Statistics of variables

Mean

Std. Deviation

\begin{tabular}{l|r|r}
\hline Disgusting & 3.8573 & .66599 \\
\hline Sexual & 3.7604 & .66726 \\
\hline Profanity & 3.7883 & .68241 \\
\hline Vulgarity & 3.9252 & .73398 \\
\hline Impropriety & 3.6752 & .67259 \\
\hline Moral & 3.7355 & .71096 \\
\hline Religious & 3.8753 & .68026 \\
\hline Consumer & 3.7262 & .72045 \\
\hline Valid N (listwise) & & \\
\hline
\end{tabular}

\subsection{Hypothesis Testing}

In order to validate hypotheses of study and define their existence between rejection and acceptance, multiple statistical tests were carried out as in the following section.

\section{Main hypothesis \\ H: Shockvertising has the ability to influence consumer behavior}

Table 3.Testing Main Hypotheses

\section{Model Summary}

\begin{tabular}{|c|c|c|c|c|c|c|c|}
\hline Model & \multicolumn{2}{|c|}{$\mathrm{R}$} & R Square & \multicolumn{2}{|c|}{ Adjusted R Square } & \multicolumn{2}{|c|}{ Std. Error of the Estimate } \\
\hline 1 & & .872 & & & .757 & & .35545 \\
\hline \multicolumn{8}{|c|}{ ANOVA } \\
\hline Model & & Sum & Squares & $\mathrm{df}$ & Mean Square & $\mathrm{F}$ & Sig. \\
\hline \multirow[t]{3}{*}{1} & Regression & & 169.751 & 7 & 24.250 & 191.941 & $.000^{\mathrm{b}}$ \\
\hline & Residual & & 53.443 & 423 & .126 & & \\
\hline & Total & & 223.194 & 430 & & & \\
\hline
\end{tabular}

\section{Coefficients}

\begin{tabular}{|c|c|c|c|c|c|c|}
\hline \multirow{2}{*}{\multicolumn{2}{|c|}{ Model }} & \multicolumn{2}{|c|}{ Instandardized Coefficients } & \multirow{2}{*}{$\begin{array}{c}\text { Coefficients } \\
\text { Beta }\end{array}$} & \multirow[b]{2}{*}{$\mathrm{t}$} & \multirow[b]{2}{*}{ Sig. } \\
\hline & & B & Std. Error & & & \\
\hline \multirow[t]{4}{*}{1} & (Constant) & -.124 & .115 & & -1.083 & .279 \\
\hline & Disgusting & -.030 & .040 & -.028 & -.758 & .449 \\
\hline & Sexual & -.080 & .047 & -.075 & -1.729 & .085 \\
\hline & Profanity & .254 & .046 & .240 & 5.577 & .000 \\
\hline
\end{tabular}




\begin{tabular}{l|l|l|l|r|r|r}
\hline Vulgarity & .086 & .040 & .088 & 2.179 & .030 \\
\hline Impropriety & .048 & .045 & .045 & 1.066 & .287 \\
\hline Moral & .115 & .042 & .114 & 2.773 & .006 \\
\hline Religious & .610 & .043 & .576 & 14.121 & .000 \\
\hline
\end{tabular}

In table (3) above, multiple regression was employed and it revealed that the $\mathrm{F}$ value was significant at 0.05 level, this result meant "Shockvertising has the ability to influence consumer behavior", with high correlation $(\mathrm{R})=$ 0.872 as well as the independent variables explained $76.1 \%$ of the variance in the dependent variable.

Sub-hypotheses:

H1: Disgusting Images has the ability to influence consumer behavior

H2: Sexual references has the ability to influence consumer behavior
H3: Profanity has the ability to influence consumer behavior

H4: Vulgarity has the ability to influence consumer behavior

H5: Impropriety has the ability to influence consumer behavior

H6: Moral offensiveness has the ability to influence consumer behavior

H7: Religious taboos has the ability to influence consumer behavior

Table 4. Sub-hypotheses Testing

Sub-

\begin{tabular}{lll|lll} 
hypotheses & \multicolumn{1}{c}{$\mathrm{R}$} & \multicolumn{2}{c}{ R Square } & \multicolumn{1}{c}{ S } & Sig. \\
\hline 1 & .593 & .351 & 232.076 & .000 \\
\hline 2 & .641 & .411 & 299.035 & .000 \\
\hline 3 & .724 & .524 & 472.326 & .000 \\
\hline 4 & .672 & .452 & 353.384 & .000 \\
\hline 5 & .705 & .496 & 422.747 & .000 \\
\hline 6 & .711 & .505 & 437.906 & .000 \\
\hline 7 & .833 & .693 & 970.455 & .000 \\
\hline
\end{tabular}

Linear Regression was used to test each of the sub hypothesis; following results were found:

$1^{\text {st }}$ hypothesis: it was found that $\mathrm{F}$ value was significant at 0.05 level, this gave an indication that "Disgusting Images has the ability to influence consumer behavior" with medium correlation $(\mathrm{R})=$ 0.593 , as well as the independent variable explains $35.1 \%$ of the variance in the dependent variable.

$2^{\text {nd }}$ hypothesis: it was found that $\mathrm{F}$ value was significant at 0.05 level meaning that "Sexual references has the ability to influence consumer behavior", and with a medium correlation (R) = 0.641 , as well as the independent variable explained $41.1 \%$ of the variance in the dependent variable.

$3^{\text {rd }}$ hypothesis: it was found that $\mathrm{F}$ value was significant at 0.05 level and "Profanity has the ability to influence consumer behavior", with high correlation $(\mathrm{R})=0.724$, as well as the independent variable explained $\mathbf{5 2 . 4 \%}$ of the variance in the dependent variable.

$4^{\text {th }}$ hypothesis: it was found that $\mathrm{F}$ value was significant at 0.05 level and that "Vulgarity has the ability to influence consumer behavior" with high correlation $(\mathrm{R})=0.672$, as well as the independent variable explains $45.2 \%$ of the variance in the dependent variable.

$5^{\text {th }}$ hypothesis: it was found that $\mathrm{F}$ value was significant at 0.05 level, this indicated that "Impropriety has the ability to influence consumer behavior", with high correlation $(\mathrm{R})=0.705$ as well as the independent variable explains $45.2 \%$ of the variance in the dependent variable.

$6^{\text {th }}$ hypothesis: it was found that $\mathrm{F}$ value was significant at 0.05 level, and that "Moral offensiveness has the ability to influence consumer behavior", with high correlation $(\mathrm{R})=0.711$, as well as the independent variable explains $50.5 \%$ of the variance in the dependent variable.

$7^{\text {th }}$ hypothesis: it was found that $\mathrm{F}$ value was significant at 0.05 level, it was indicated that "Religious taboos has the ability to influence consumer behavior", with high correlation $(\mathrm{R})=$ 0.833 , as well as the independent variable explains $69.3 \%$ of the variance in the dependent variable.

\subsection{Discussion}

Current study aimed at examining the influence of shockvertising on consumer behavior from perspective of Jordanian consumers in Jordan. 
Utilizing a questionnaire; (431) individuals responded to statements of questionnaire and SPSS was used in order to analyze gathered data. Results of study found out that individuals had high awareness of shockvertising as their responses appeared to be higher than mean of scale 3.00 which was positively seen from a statistical perspective.

The main hypothesis of study was accepted and study results indicated that "Shockvertising has the

Religious taboos scored a variance relationship of (69.3\%).

consumer behavior through shockvertising; this variable scored a relationship variance of (52.4\%)

Other variables also appeared to be influential which included (Moral offensiveness, Vulgarity, Impropriety, Sexual references and Disgusting Images) which scored a relationship variance of $(50.5 \%, 45.2 \%, 45.2 \%, \quad 41.1 \%$ and $35.1 \%)$ respectively.

\section{Shockvertising can Severely Influence Consumer Behavior}

The study found that there is a statistically significant effect of the negative trend towards "shock advertising" and about the "advertised brand" on the consumer behavior to the advertisement from not buying, negative verbal communication and boycott, which confirms the psychological impact stages of the advertising message of the shocking advertisement and that the ads don't not lead to desire and persuasion, which led to changing the formula of the psychological effect stages of the advertising message to AISDA, namely Attention, Insert, Share, Desire, and Action. Results of study indicated that shockvertising plays on the emotional and cognitive part of human comprehension which plays a role in developing emptions of gross, passion, disgust, anger and humiliation when seeing the ad. From that point, the way shockvertising appear is through penetrating the conscious of individuals and travel into their subconscious causing their feeling to appear on the surface. Study also revealed that sharing of the advertisement came after attention and interest, which is what the shocking advertisement seeks, i.e. attracting attention by penetrating the competitive chaos, but when the consumer shares the advertisement through social networking sites and those ads spread like buzz viruses, in this case, they provoke the consumer, which results in negative feelings and in that case no desire and persuasion develop. Also, among the results of the study is the formation of a negative trend towards the shocking advertisement and the declared mark for the study sample, most of which according to the analysis, and the expected reaction for each category, the ability to influence consumer behavior" which was explained by a variance of (76.1\%).

Among the chosen variables of shockvertising including (Disgusting Images, Sexual References, Profanity/Obscenity, Vulgarity, Impropriety, Moral Offensiveness and Religious Taboos) it was revealed that all variables were found to influential on consumer behavior, the most influential variable of all appeared In the $2^{\text {nd }}$ rank of influence; it appeared that Profanity played a role in changing conscious consumer is the consumer who has awareness of the advertiser's tactic and that it does not convince him, and in that case the advertisement is not effective, which is what the study actually found in the presence of a statistically significant effect of the negative trend towards shocking advertising on the consumer's response to the advertisement from not buying negative verbal communication and boycott, indicating that the shocking advertisement is fraught with danger.

\section{When It Comes to Religion; It's A Shock!}

When comparing and contrasting between influences of shockvertising through its variables on consumer behavior; it appeared that the most influential variable of all is religious taboos. Results indicated that the hypothesis articulated "Religious taboos has the ability to influence consumer behavior" was able to explain (69.3\%) of the variance in the dependent variable and appeared to be the strongest of all, meaning that consumers' behavior in terms of purchasing, repurchasing and word of mouth would be deeply influenced if the advertisement touched their religion or any of its sacred symbols as it appeared in table (12). This result was totally predictable considering the environment in which current study was applied (Jordanian consumer) where there is a deep consideration to religions and respect to holy believes.

\subsection{Conclusion and Recommendations}

A successful advertisement is the advertisement that fulfills its functions of attracting attention, arousing interest and desires, up to persuading the content of the advertising message and responding to it, and because shockvertising is one of the multiple means of drawing attention to an issue, idea, product or service, many organizations have resorted to it through the element of trauma.

Study showed that although the use of shockvertising is a growing phenomenon that has spread in the recent period significantly, but the results related to it in terms of positive or negative impact on individuals are still disparate between 
supporters and opponents, but its superior ability to attract attention is clear and cannot be discussed.

Based on previously presented results and discussion, current study recommended the following:

- In order for the shockvertising to have a positive impact, it must be away from religious symbols and sacred ideas of individuals because using their sanctities makes them feel offended

- Shockvertising needs to be understandable, simple and not complex in order to have the desired impact on consumers.

- Shockvertising should be used in a way that approximates the truth and not in a catastrophic manner that will alienate the person and show negative feelings within them.

\section{References}

[1]. Banyte, J., Paskeviciute, K., \& Rutelione, A. Features of shocking advertising impact on consumers in commercial and social context. Innovative Marketing, Vol 10, No 2, 2014, pp. 35-46.

[2]. Cockrill, A., \& Parsonage, I. Shocking people into action: Does it still work?: An empirical analysis of emotional appeals in charity advertising. Journal of Advertising Research, Vol 56, No 4, 2016, pp. 401-413.

[3]. Dahl, D. W. (2018). Shock charity campaigns: Building our understanding on their effectiveness: Comments on "Emotions and Prosocial Behaviors: A Study of the Effectiveness of Shocking Charity Campaigns" by Jeanne Albouy. Recherche et Applications en Marketing (English Edition), Vol, 33, No, 1, 2018, pp. 88-91.

[4]. Du Plessis, N. Examining Shock Advertising in a South African context, research paper, Vega School of Brand Leadership. 2016

[5]. Friendly Stock. Shockvertising by united colors of Benetton [Image]. Retrieved from https://friendlystock.com/top-tencontroversial-united-colors-of-benettonads/, 2020

[6]. Ghose, A., \& Todri, V. Towards a digital attribution model: Measuring the impact of display advertising on online consumer behavior. Available at SSRN 2672090, 2015

[7]. Giroux, H. A., \& Robbins, C. G. Consuming Social Change: The "United
Colors of Benetton". In Giroux Reader (pp. 97-116). Routledge, 2015

[8]. Hagenbuch, D. J. Should Advertising Shock? Journal of Biblical Integration in Business, Vol 18, No. 2, 2015.

[9]. Handley, L. Burger King's moldy Whopper ad is dividing marketing experts. $C N B C$.

Retrieved from https://www.cnbc.com/2020/02/20/burgerkings-moldy-whopper-ad-is-dividingmarketing-experts.html, 2020

[10]. Hashem, T. How Do Customers Digest Pictorial ADS from A Psychological Perspective? Global Journal of Business Research, Vol, 10, No, 4, 2016, pp. 43-54.

[11]. Hashem, T. Impact of using humor advertisement on airline customers' mental image. Innovative Marketing, Vol 13, No 3, 2017, pp. 25-32.

[12]. Hashem, T. N., \& Hamdan, F. I. Measuring service quality level in the Jordanian telecommunication sector from its customers' perspective using the SERVPERF scale. European Journal of Business and Social Sciences, Vol, 5, No 12, 2017, pp. 15-27.

[13]. Lee, M. S., Septianto, F., Frethey-Bentham, C., \& Gao, E. Condoms and bananas: Shock advertising explained through congruence theory. Journal of Retailing and Consumer Services, Vol 57, 2020, 102228.

[14]. Machová, R., Huszárik, E. S., \& Tóth, Z. The role of shockvertising in the context of various generations. Problems and perspectives in management, Vol, 13, No, 1, 2020, pp. 104-112.

[15]. Machova, R., Seres, H. E., \& Toth, Z. Shockvertising in selected European countries: Hofstede's dimensions analysis. Актуальні проблеми економіки, Vol 5, No 11, 2015, pp. 32-42.

[16]. Madni, A. R., Hamid, N. A., \& Rashid, S. M. Influence of Controversial Advertisement on Consumer Behavior. The Journal of Commerce, Vol 8, No, 1-2, 2016, pp. 14.

[17]. Matusitz, J., \& Forrester, M. PETA making social noise: A perspective on shock advertising. Portuguese Journal of Social Science, Vol, 12, No, 1, 2013, pp. 85-100.

[18]. Parry, S., Jones, R., Stern, P., \& Robinson, M. 'Shockvertising': An exploratory investigation into attitudinal variations and emotional reactions to shock advertising. Journal of Consumer 
Behaviour, Vol, 12, No, 2, 2015, pp. $112-$ 121.

[19]. Rogers, K., \& Weber, M. Shock Tactics: Perceived Controversy in Molleindustria Persuasive Games. In International Conference on Persuasive Technology, 2018 (pp. 193-199). Springer, Cham.

[20]. Srivastava, R. K. Comparing the three types of approach of advertising in brand building in emerging markets. Journal of Strategic Marketing, 2020, pp. 1-14.

[21]. Ulman, M. Benetton i shockvertising. Marketing $w$ praktyce, Vol, 3, No 1, 2017, pp. 38-39.

[22]. Virvilaite, R., \& Matuleviÿiene, M. The impact of shocking advertising on consumer buying behavior: empirical study of Lithuanian consumers. Innovative Marketing, Vol, 9, No, 2, 2013, pp. 47-56.

[23]. Yan, S., \& Chapa, S. Exploring the use of shock advertising by for-profit and nonprofit organisations in China. Journal of Cultural Marketing Strategy, Vol, 5, No, 1, 2020, pp. 11-21.

\section{Creative Commons Attribution License 4.0}

(Attribution 4.0 International, CC BY 4.0)

This article is published under the terms of the Creative Commons Attribution License 4.0

https://creativecommons.org/licenses/by/4.0/deed.en _US 